\title{
DEFORMATION AND CRUSHING OF PARTICLES OF CEMENT TREAT GRANULATE SOIL
}

\author{
Phan Huy Dong ${ }^{\text {i) }}$, Kimitoshi Hayano ${ }^{\text {ii) }}$, Yoshiaki Kikuchi ${ }^{\text {iii) }}$, \\ HIDENORI TAKAHASHI ${ }^{\text {iv) }}$ and YOSHIYUKI MORIKAWA ${ }^{\text {v) }}$
}

\begin{abstract}
Cement Treat Granulate Soil (CTGS), a new artificial granular material, has been developed recently by mixing the dredged marine clay with appropriate amounts of cement and polymer. The CTGS particles are crushable and deformable, thus forming a compressible material. Besides being a lightweight material, CTGS is a granular material, and is therefore expected to be applied in reclamations or as a back fill or subsoil materials. This study investigates the deformation and crushing of the CTGS particles and their effects on the stress-strain behaviors. The comprehensive investigation of the principle of treatment, the micro-structure of particles, triaxial stress-strain behaviors, induced particle crushing and particle deformation are first presented via the experimental work done on two types CTGS produced from a lean-mixture design of cement and polymer. Subsequently, the results of X-ray Computer Topography (CT) scanners along with triaxial CD tests on CTGS and conventional gravel having rigid particles are presented. The test results reveal local failure mechanisms between the individual particles of the CTGS and gravel, from which the failure models of the granular materials formed by deformable and crushable grains and non-crushable grains are interpreted.
\end{abstract}

Key words: cement treat granulate soil, dredged marine clay, particle crushing, particle deformation, vesicular particle, X-ray CT scanner test (IGC: D6/D10)

\section{INTRODUCTION}

The sheer scale of the practice of dumping dredging materials in marine area has made it a serious geo-environmental problem in various countries. High price has to be spent for dumping the waste soil at off-shore or inland landfill. Effort has been made to reduce the bulk volume or to utilize the dredging materials for construction materials, with a focus on treating soils so that they have useful engineering properties at reasonable production costs.

Basically, the engineering properties of dredged soils are improved by cement or chemical treatment. Methods of treated soils with cement have been extensively studied by numerous researchers (e.g., Tsuchida et al., 1996; Miura et al., 2001; Tang et al., 2001; Lorenzo and Bergado, 2004; Horpibulsuk et al., 2005; Rekik and Boutouil, 2009), in which both improving the efficiency of treatment and cost reduction have been thoroughly discussed. Cement treated soils have been practically applied in reclamation projects and in road constructions (Tatsuoka et al., 1997; Tang et al., 2001; Kamali et al., 2008). However, among the shortcomings of reusing dredged soils are the high treatment cost, and disparities between supply and demand in time and location (Tang et al., 2001).

The competitiveness of cement treated soils with excavation soils can be improved by investigating its applicability for construction in addition and improving both technique and site execution. As a new approach to utilize dredged marine clay for construction, CTGS, a granular material, is produced from the dredged clay by mixing with proper amounts of cement and polymer. Previous studies (Dong et al., 2009, 2010a, 2010b; Takahashi et al., 2010) demonstrated that CTGS is a lightweight material with the good characteristics of the granular materials (e.g., ease of compaction, good drainage and ease of transportation), and moreover, it can be produced from lean-amounts of cement and polymer for cost reduction. Therefore, it is expected to be applied in reclamations, or as backfill and subgrade materials. However, they also found that deformation and crushing of the CTGS particles are key factors influencing on its engineering properties. In order to gain a better understanding of the geotechnical properties of CTGS, this study aims to investigate the deformation and crushing of

i) Ph.D candidate, Department of Civil Engineering, Yokohama National University, Japan.

Associate Professor, ditto (hayano@ynu.ac.jp).

iii) Ph.D, Geotechnical and Structural Engineering Department, Port and Airport Research Institute, Japan.

iv) $\mathrm{Ph} . \mathrm{D}$, ditto

v) Ph.D, ditto.

The manuscript for this paper was received for review on June 18, 2010; approved on February 8, 2011.

Written discussions on this paper should be submitted before May 1, 2012 to the Japanese Geotechnical Society, 4-38-2, Sengoku, Bunkyo-ku,

Tokyo 112-0011, Japan. Upon request the closing date may be extended one month. 
the CTGS particles and their effects on stress-strain behaviors. Firstly, the principle of treatment, the production method and the micro-structure characteristics of the CTGS particles produced from two types of lean-mixture design of cement and polymer are presented. The stressstrain behaviors, the particle crushing and the particle deformation of the CTGS are then characterized based on a set of the triaxial CD tests. In an attempt to clarify the effects of particle crushing and particle deformation on triaxial stress-strain behaviors, the X-ray computer tomography (CT) scanners associated with the triaxial $\mathrm{CD}$ tests were used to visually observe the micro-structure deformation mechanisms inside the specimens during triaxial loading.

\section{FUNDAMENTALS OF CTGS}

\section{Materials}

The material used in this study was produced from deposited clay dredged from Kawasaki port, Japan. It is hereinafter referred to as Kawasaki clay. Normal Portland cement (an ASTM type of cement) was used to stabilize and solidify the soft clay. As provided by manufacturer, the specific gravity $G_{\mathrm{s}}$ is 3.15 , and the compressive strength after 3 days and 7 days is $12400 \mathrm{kPa}$ and 19300 $\mathrm{kPa}$, respectively. The high consistency Kawasaki clay was granulated using the Aqupaana (partially neutralized polyacrylic acid) polymer with a bulk density in the range of 0.85 to $0.95 \mathrm{~g} / \mathrm{cm}^{3}$, particle size varying from 50 to 100 $\mu \mathrm{m}$ and a $0.2 \%$ aqueous solution viscosity of $500-800$ $\mathrm{mPa}$.s. Some physical properties of the Kawasaki clay are summarized in Table 1, and its grain size distribution curve is shown later in this paper (see Fig. 3).

\section{Principle of Treatment}

The treatment mechanism involves the generation of a cement bond by hydration and the pozzolanic reactions of cement and water. This cement bonding binds the fine particles of clay in a monolithic solid to a high structural integrity (Chew et al., 2004; Horpibulsuk et al., 2005). Meanwhile, as the fine polymer particles absorb water molecules (free water), they in effect become an adhesive, accumulating and bonding the fine particles of clay as granular particles. The CTGS particles gradually achieve a certain strength after a certain curing time.

Recent work on cement treated clay has demonstrated that the strength and stiffness of treated soil are governed by the amounts of cement clay water, the ratio of water to cement, curing time and the presence of organic matter in

Table 1. Physical properties of Kawasaki clay

\begin{tabular}{l|c}
\hline \multicolumn{1}{c|}{ Properties } & Value \\
\hline Plastic limit, $w_{\mathrm{P}}(\%)$ & 23.0 \\
Liquid limit, $w_{\mathrm{L}}(\%)$ & 48.6 \\
Specific density, $\rho_{\mathrm{s}}\left(\mathrm{g} / \mathrm{cm}^{3}\right)$ & 2.68 \\
Sand (\%) & 14.0 \\
Silt (\%) & 42.0 \\
Clay (\%) & 44.0 \\
\hline
\end{tabular}

the original dredged clay, etc (Tremblay et al., 2002; Chew et al., 2004; Kamali et al., 2008; Rekik and Boutouil, 2009). Some indices have thus been proposed to characterize the influences of these factors, such as the water/cement ratio defined as water mass divided by cement mass (Horpibulsuk et al., 2005; Sariosseiri and Muhunthan, 2009), the after-curing void/cement ratio (Lorenzo and Bergado, 2004), the voids/cement ratios represented by the ratio of volume of voids to volume of cement (Fonseca et al., 2009), etc. In principle, the strength and stiffness of the CTGS particles are governed by the cement and polymer bonds. A sufficient amount of polymer is required to granulate the dredged clay, though too much polymer may weaken and soften the particles since the particle bond is weaker than the cement bond. On the other hand, a sufficient amount of water in the mixture is needed not only for cement hydration and the pozzolanic reactions but also for polymer bonding. Consequently, the size, shape, strength and stiffness of the CTGS particles depend on the ratio of cement to polymer, and the ratio of water to cement and polymer.

\section{Production Method}

A detailed investigation of all the influencing factors is beyond the scope of this study but should be considered in further work for practical use. A mixing procedure is herein proposed, from the results of a series of trial mixing tests conducted on various mixture designs of cement, polymer and Kawasaki clay, i.e., Kawasaki clay was first stirred to be a homogeneous slurry whilst its water content was adjusted to be $60 \%\left(1.2 w_{\mathrm{L}}\right)$, and subsequently mixed with the polymer for two minutes, followed by five minutes of mixing with the cement by a small blade mixing machine. This time of mixing was required to ensure the homogeneous condition of mixture. The mixture was re-mixed again for one minute after an hour from the first mixing to prevent re-bonding between particles. After mixing thoroughly, the materials were then cured in trays covered by a plastic sheet to keep a constant water content at room temperature.

\section{Mixing Proportions and Physical Properties}

Previous study by Takahashi et al. (2010) investigated the particle strength of a single CTGS particle based on a series of uniaxial compression tests conducted on various single particles with the average diameter $D_{50}$, about 5 $\mathrm{mm}$. In their study, the CTGS was also produced from Kawasaki clay mixed with different proportions of cement and polymer. The single particle was placed between two hardened platens and compressed continuously at a constant rate of displacement. The vertical loaddeformation relation was recorded during vertical loading, as shown in Fig. 1(a) for some typical cases. Particle strength, $\sigma_{\mathrm{f}}$, was calculated based on the first peak value $F_{\max }\left(\sigma_{\mathrm{f}}=4 F_{\max } / \pi d^{2}, d\right.$-diameter of particle) whereas particle stiffness was determined by secant deformation modulus at the peak. After examining the influences of number of particles, they proposed reliable ranges of particle strength at different mixing proportions by statistical 


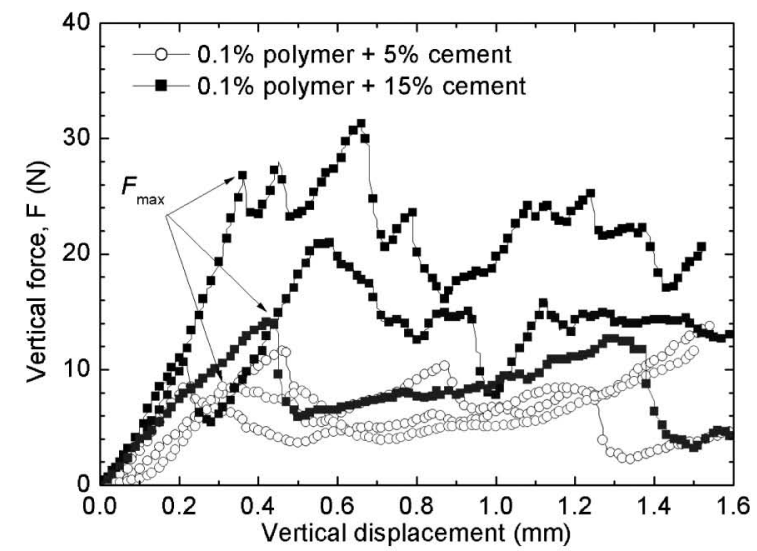

(a)

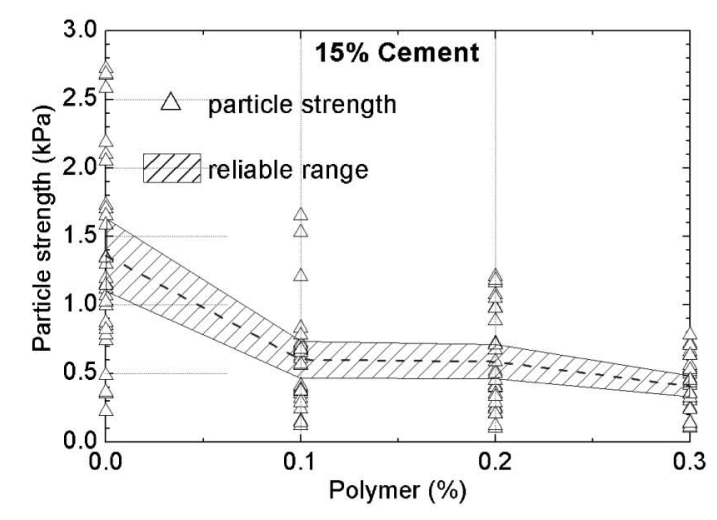

(c)

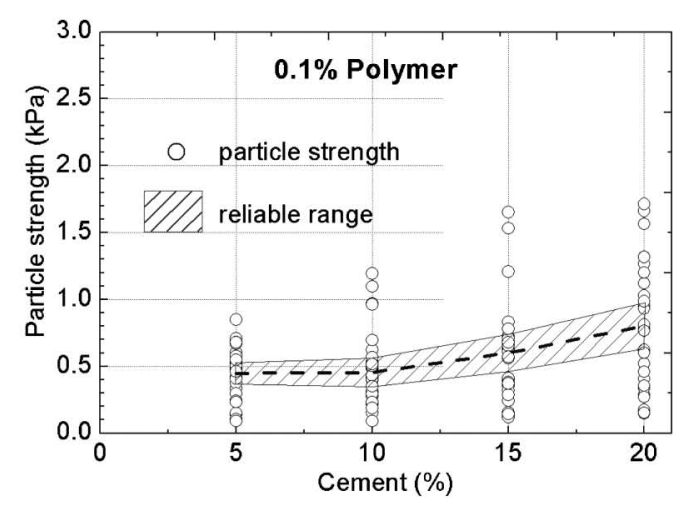

(b)

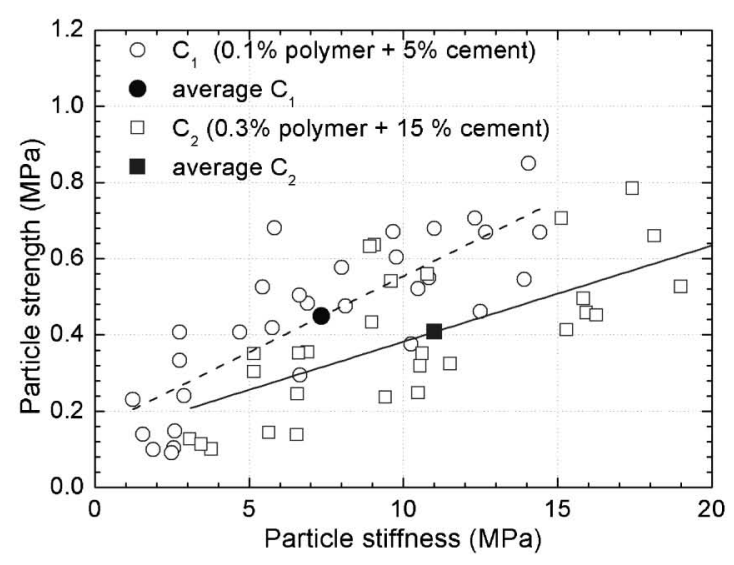

(d)

Fig. 1. (a) Typical load-displacement curves of some particles, (b) Particle strength at different percentages of cement with $0.1 \%$ of polymer, (c) Particle strength at different percentages of polymer with $15 \%$ of cement and (d) relationship between particle strength and particle stiffness (Takahashi et al., 2010)

analysis on the test results of 30 arbitrarily selected particles. It can be seen from Figs. 1(b) and 1(c) that particle strength increased with the amount of cement and slightly decreased with the amount of polymer.

As an attempt to produce materials at reasonable cost, this study selected two types of CTGS, which were produced from lean-mixture designes of cement and polymer, as follows: (i) $\mathrm{C}_{1}$ type: $5 \%$ cement, $0.1 \%$ polymer to the wet weight of clay corresponding to $45 \mathrm{~kg}$ of cement and $0.89 \mathrm{~kg}$ of polymer for $1 \mathrm{~m}^{3}$ of clay, (ii) $\mathrm{C}_{2}$ type: $15 \%$ cement, $0.3 \%$ polymer to the wet weight of clay, or $124 \mathrm{~kg}$ of cement and $2.5 \mathrm{~kg}$ of polymer per $1 \mathrm{~m}^{3}$ of clay. These amounts of cement are quite similar to those using in cement treated soil methods, from 50 to $200 \mathrm{~kg} / \mathrm{m}^{3}$ as demonstrated by Chiu et al. (2008). The ratios of water/cement in $\mathrm{C}_{1}$ and $\mathrm{C}_{2}$ are 7.5 and 2.5, respectively. In Fig. 1(d), from Takahashi et al. (2010), the particle stiffness and particle strength of $C_{1}$ and $C_{2}$ vary in wide scatters. The average values of particle strength are almost similar, about $0.4 \mathrm{MPa}$, which are much lower than those of natural sands, which were reported as being in the range of 28 to $46 \mathrm{MPa}$ by Yoshimoto et al. (2010).
However, the average value of the particle stiffness of $\mathrm{C}_{2}$ is substantially greater than that of $\mathrm{C}_{1}$.

Figure 2 shows the Kawasaki clay and photos of $C_{1}, C_{2}$ types with corresponding microscopic photos of typical particles, and the gravel which is hereinafter used for referential framework. The $\mathrm{C}_{1}$ and $\mathrm{C}_{2}$ particles are both regular spherical shapes, some of which are bonded with others. The grading curves of original Kawasaki clay, $\mathrm{C}_{1}$, $\mathrm{C}_{2}$ and the gravel are shown in Fig. 3. It can be seen that the clay composed by fine particles was converted to coarse-grain granular materials, and the particle size distributions of $\mathrm{C}_{1}$ are $\mathrm{C}_{2}$ types are slightly different. According to the JGS classifications, $\mathrm{C}_{1}$ can be classified as G-S and $\mathrm{C}_{2}$ is GS.

Some physical properties of the CTGS are summarized in Table 2. It is here noted that the CTGS was cured in airtight condition; the presented values of water content are obtained from samples after curing and therefore refer to the so-called natural water content. The maximum void ratio was determined based on JGS (0162: 2009) whereas the minimum void ratio was evaluated by a vibration method as an attempt to obtain maximum den- 


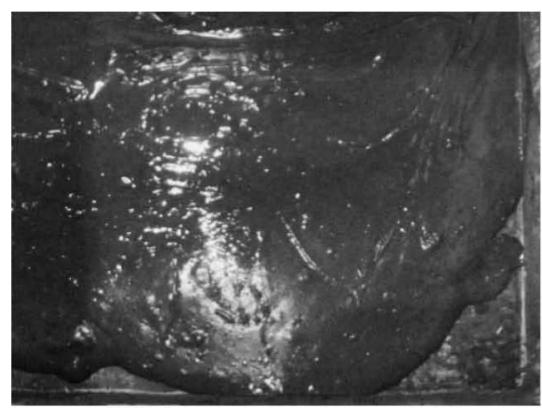

(a)

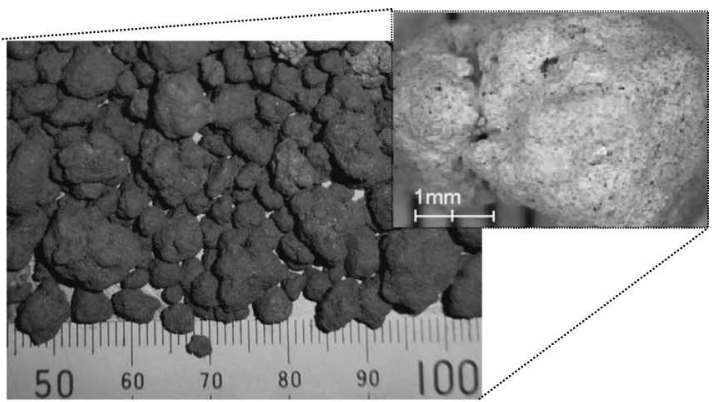

(b)

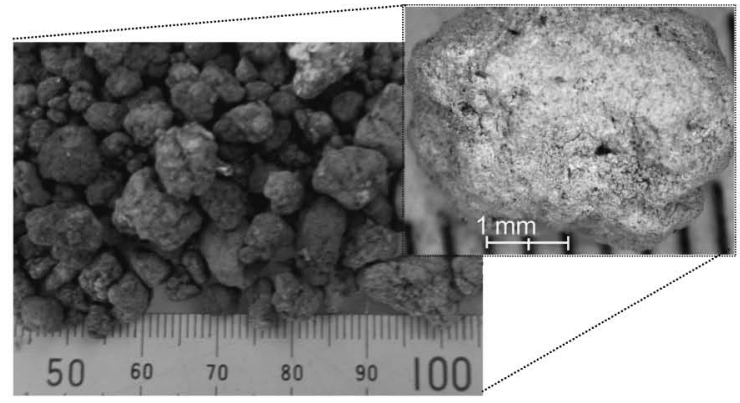

(c)

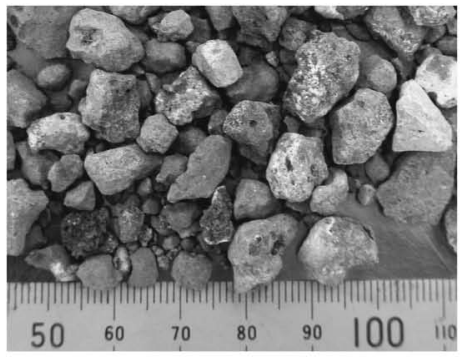

(d)

Fig. 2. (a) Original Kawasaki clay, (b) $C_{1}$ type, (c) $C_{2}$ type and (d) gravel

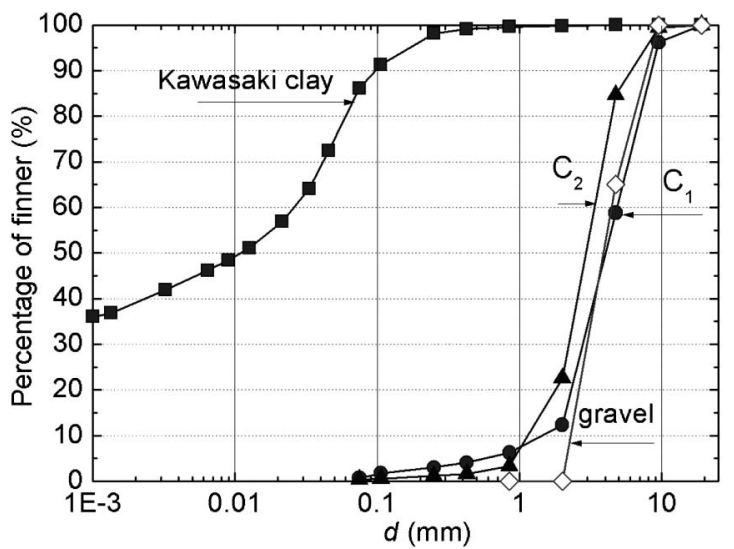

Fig. 3. Grading curves of materials

Table 2. Physical properties of CTGS

\begin{tabular}{|c|c|c|}
\hline Properties & $\mathrm{C}_{1}$ & $\mathrm{C}_{2}$ \\
\hline Natural water content, $w(\%)$ & 44.8 & 39.2 \\
\hline $\mathrm{pH}$ & 10.64 & 11.34 \\
\hline$d_{60}(\mathrm{~mm})$ & 4.98 & 3.39 \\
\hline$d_{10}(\mathrm{~mm})$ & 1.56 & 1.21 \\
\hline Coefficient of uniformity, $C_{\mathrm{c}}$ & 3.14 & 2.83 \\
\hline Maximum void ratio, $e_{\max }$ & 3.35 & 2.98 \\
\hline Minimum void ratio, $e_{\min }$ & 2.44 & 2.23 \\
\hline Maximum dry density, $\rho_{\text {dmax }}\left(\mathrm{g} / \mathrm{cm}^{3}\right)$ & 0.811 & 0.834 \\
\hline Minimum dry density, $\rho_{\text {dmin }}\left(\mathrm{g} / \mathrm{cm}^{3}\right)$ & 0.641 & 0.677 \\
\hline
\end{tabular}

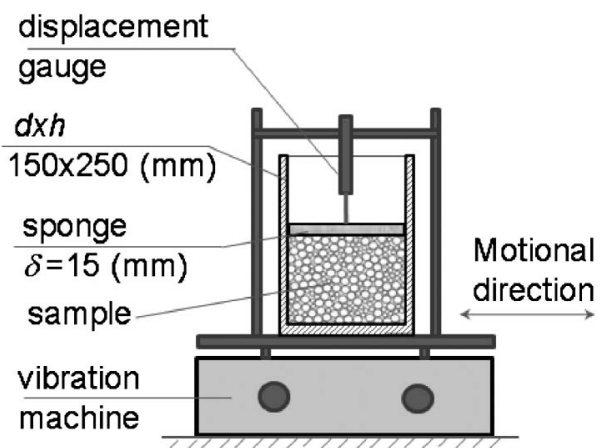

Fig. 4. The model of the vibration test sity with minimum particle crushing. The test model is depicted in Fig. 4 consists of a cylinder, $300 \mathrm{~mm}$ in height and $150 \mathrm{~mm}$ in diameter, fixed to a frame above a vibration machine. The material was placed into the cylinder and leveled by a lightweight sponge on the top surface that could be freely moved along the vertical direction. While being vibrated horizontally, the GCTS particles were rearranged and filled the voids between the other particles associated with the reduction of void volume as denser packing took place. The vertical movement of the sponge was monitored by a displacement gauge. The densest configuration of the material was attained for a certain time of vibration until a stable level of vertical displacement or no volume reduction was observed. The maximum density can be determined from a known mass of material and its volume at the densest configuration. 
The values of minimum void ratio in Table 2 were obtained from a series of tests conducted on different samples when the influences of frequency of the horizontal vibration, water content and mass of CTGS were examined.

\section{VESICULAR CHARACTERISTICS OF THE CTGS PARTICLES}

It can be seen from the microscopic photos of typical CTGS particles in Figs. 2(b) and 2(c) that some clearly open hollows appear on the surface of the CTGS particles. This may lead to the existence of a network of interparticle voids, some of which may be connected and open to the surface of the particle (intra-open voids) and others are closed in the form of intra-closed voids, in addition to the voids between particles (connected voids) in the CTGS particles. The interparticle voids may have been generated by the air and free water in the clay during mixing. It is important to quantify the portions of the interparticle voids in order to clearly understand the engineering properties of this material. Subsequently, methods to evaluate the portions of these voids are herein proposed.

\section{Intra-closed Voids}

A series of particle density tests was carried out on CTGS samples with different particle sizes by the standard technique. A known mass of CTGS is put into a pycnometer and then boiled for a few hours to remove air in the connected voids and the interparticle voids. Remarkably, samples with a maximum particle size of $0.075 \mathrm{~mm}$ were obtained by crushing larger particles and using a $0.075 \mathrm{~mm}$ sieve. Samples were dried in an oven at $110^{\circ} \mathrm{C}$ until no change in weight was observed, and it is expected that internal free water was fully desiccated since free water can be evaporated by heating. A decreasing tendency of particle density in both $C_{1}$ and $C_{2}$ to maximum particle size was also observed, as shown in Fig. 5. Although it could be partly due to the inhomogeneity of the CTGS particles, it indicates the existence of the intraclosed voids in larger particles, into which no water could

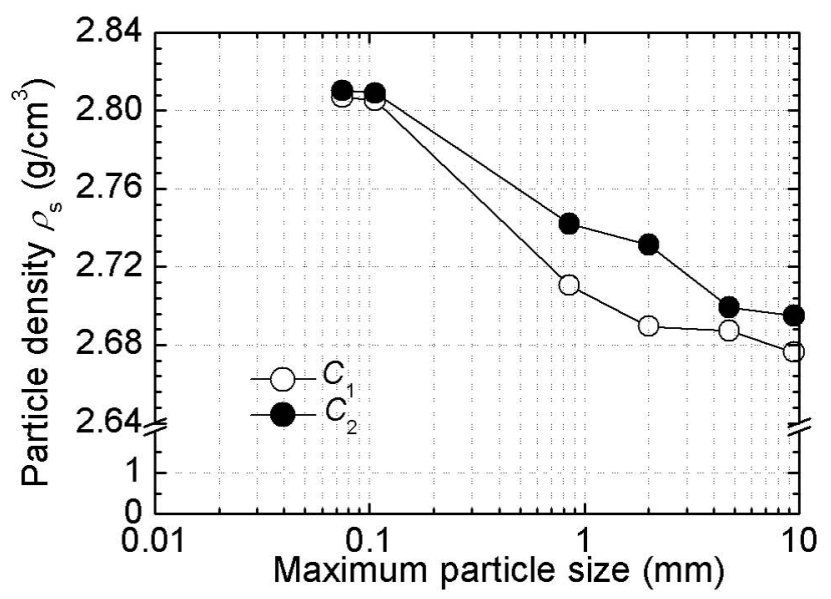

Fig. 5. Variation of the specific density with maximum particle size penetrate. This reduction of particle density to particle size was also demonstrated as an effect of the interparticle voids in granular material with vesicular particles, such as volcanic sand (Pender et al., 2006), and clinker ash (Yoshimoto et al., 2010).

On the assumption that the intra-closed voids fully vanish when the samples are crushed and absolutely no water can penetrate into them, the volume of the intraclosed voids can be calculated from the variation of particle density in the following way:

$$
V_{\mathrm{ic}}=\left(\rho_{\mathrm{sc}}-\rho_{\mathrm{s}}\right) V_{\mathrm{sc}} / \rho_{\mathrm{s}}=\left(\rho_{\mathrm{sc}}-\rho_{\mathrm{s}}\right) V_{\mathrm{s}} / \rho_{\mathrm{sc}}
$$

where $V_{\text {ic }}$ is volume of the intra-closed voids; $\rho_{\mathrm{s}}, V_{\mathrm{s}}$ and $\rho_{\mathrm{sc}}, V_{\mathrm{sc}}$ are the particle density, and the volume of the particles of the uncrushed and crushed samples, respectively, as illustrated in Fig. 6.

\section{Intra-open Voids}

A model test was set up to evaluate portions of the intra-open voids and the connected voids between particles. This model test was set up after referring to the work presented by Nakata and Miura (2007). Figure 7 shows a schematic of the apparatus, which consists of two cylinders. The inner cylinder with a diameter of $100 \mathrm{~mm}$ is used to hold the test sample and is equipped with a drain valve at the bottom. The outer cylinder, $150 \mathrm{~mm}$ in diameter, is closed at the top and is equipped with a valve at the top. The weight of the apparatus is continuously monitored by a digital balance. The CTGS samples were dried in an oven at $110^{\circ} \mathrm{C}$ until there was no change in weight due to the removal of the free water inside and between the particles. Samples were then placed into the in-

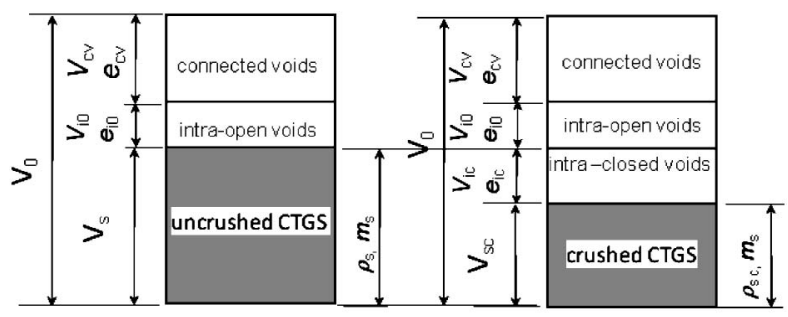

(a)

(b)

Fig. 6. Idealized phases of CTGS: (a) uncrushed sample and (b) crushed sample

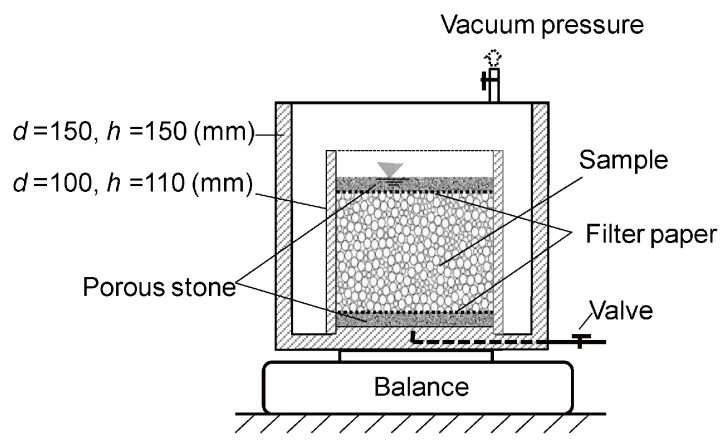

Fig. 7. Model of flow test using a vacuum 
ner cylinder by air pluviation with zero drop height. Subsequent tests were performed at a constant temperature room of $20^{\circ} \mathrm{C}$ by the following two steps:

Inflow: The samples were saturated by first passing carbon dioxide and then de-aired distilled water through the bottom tube at a very slow rate. The water level was thereafter kept at $1 \mathrm{~cm}$ over the top surface of sample; a vacuum pressure was subsequently applied until no air bubbles appeared on the side or top surface of the samples. Consequently, the water level was adjusted to be at the top surface of the upper porous stone so that the mass of water stored into a known volume of the sample could be measured by taking the mass of the initial water stored in the two porous stones, the filters and the bottom tube into account. Supposing that specimen were fully saturated and water could not penetrate into the intra-closed voids, the volume of water supply likely represents the total volume of voids made up of the connected voids between and the intra-open voids within the particles of entire sample.

Outflow: When the bottom valve is opened, the free water inside the sample was expelled by its gravity. Thus, the relationship between the water content of the samples vs. time can be monitored.

Test results interpretation: The tests were conducted on the $\mathrm{C}_{1}$ and $\mathrm{C}_{2}$ samples, with a diameter of $10 \mathrm{~cm}$, a height of $8 \mathrm{~cm}$ and almost same dried density, $\rho_{\mathrm{d}} \sim 0.73 \mathrm{~g} / \mathrm{cm}^{3}$. A similar test on the gravel (Fig. 2(d)) sample was also done for referential purpose. The results presented in Fig. 8 suggest that the relationships between the water content versus time during outflow testing have the same tendency since the water content rapidly reduces and approaches a certain value in all cases. In the CTGS cases,

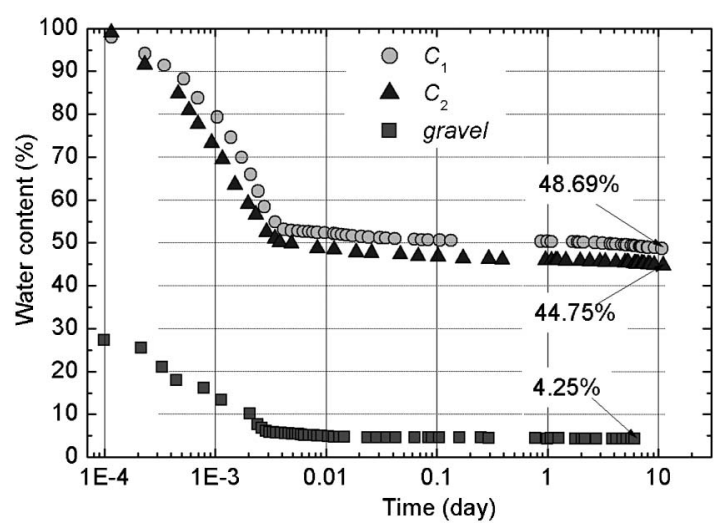

Fig. 8. Relationships between water content of specimen versus time during outflow test the values respresenting the water contents at the end of outflow test, $w_{\text {final }}$ seem reasonable since they are about $5 \%$ larger than the corresponding natural water contents showing in Table 2. These results lead to the reasonable assumption that when the bottom valve is open, the free water occupying the connected voids is easily expelled from the sample, and the rest of the water is still held in the narrow gaps of intra-open voids by capillary suction. If the above assumption is accepted, portions of the volume of the components of particles can be evaluated based on the mass of the water which was rapidly expelled, $\Delta m$, based on the following expressions:

$$
\begin{aligned}
& V_{\text {water }}=m_{\mathrm{w}} / \rho_{\mathrm{w}}=V_{\mathrm{i} 0}+V_{\mathrm{cv}} \\
& V_{\mathrm{cv}}=\Delta m_{\mathrm{w}} / \rho_{\mathrm{w}}=\Delta w m_{\mathrm{s}} / \rho_{\mathrm{w}} \\
& \Delta w=w_{\text {initial }}-w_{\text {final }} \\
& V_{\mathrm{i} 0}=V_{\text {water }}-V_{\mathrm{cv}} \\
& V_{\text {matrix }}=V_{\mathrm{sc}}=V_{0}-V_{\mathrm{ic}}-V_{\mathrm{i} 0}-V_{\mathrm{cv}}
\end{aligned}
$$

where $V_{\text {water }}, m_{\mathrm{w}}$ are the volume and the mass of water occupying the voids within the specimen, and $V_{0}, V_{\mathrm{cv}}, V_{\mathrm{i} 0}$, $V_{\text {matrix }}$ (Fig. 6) are the bulk volume of the entire sample, the connected voids, the intra-open voids and the particle matrix, respectively. Table 3 summarizes the test results, and shows the proportion in volume of each component of particles to the entire sample, $V_{0}$. It can be seen that $V_{\text {ic }}$ is relatively small and $V_{\mathrm{i} 0}$ seems to be significantly large in order greater than $V_{\text {matrix }}$ in both $\mathrm{C}_{1}$ and $\mathrm{C}_{2}$ cases. The reliability of the test result seems to be validated since $w_{\text {final }}$ as well as the $V_{\mathrm{i} 0}$ of gravel is reasonablly small.

Essentially, the CTGS particles are comprised of a high structural integrity of fine clay particles bound with others by cement and polymer bonds so that there is a network of gaps between the clay particles which are inter-connected and open to the surface of the particles while others are closed, in the form of intra-closed voids. This leads to a conceptual microstructure model of the CTGS particles as illustrated in Fig. 9. This vesicular

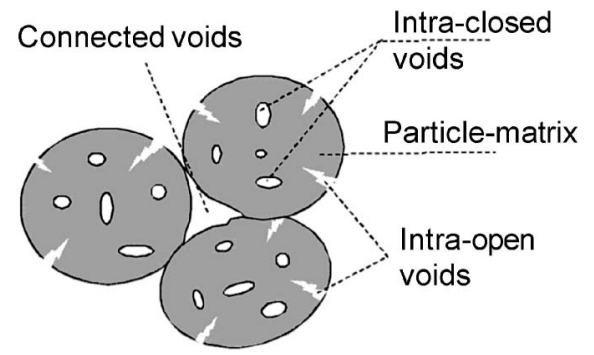

Fig. 9. Conceptual model of the CTGS particles

Table 3. Results of flow tests

\begin{tabular}{c|c|c|c|c|c|c|c|c}
\hline Type of material & $w_{\text {final }}(\%)$ & $\rho_{\mathrm{d}}\left(\mathrm{g} / \mathrm{cm}^{3}\right)$ & $\rho_{\mathrm{sc}}\left(\mathrm{g} / \mathrm{cm}^{3}\right)$ & $\rho_{\mathrm{s}}\left(\mathrm{g} / \mathrm{cm}^{3}\right)$ & $V_{\mathrm{ic}} / V_{0}(\%)$ & $V_{\mathrm{i} 0} / V_{0}(\%)$ & $V_{\mathrm{cv}} / V_{0}(\%)$ & $V_{\text {matrix }} / V_{0}(\%)$ \\
\hline $\mathrm{C}_{1}$ & 48.69 & 0.731 & 2.80 & 2.68 & 1.27 & 35.7 & 36.0 & 27.0 \\
\hline $\mathrm{C}_{2}$ & 44.75 & 0.727 & 2.81 & 2.69 & 1.15 & 33.1 & 40.1 & 27.2 \\
\hline gravel & 4.25 & 1.71 & - & - & - & 7.3 & 39.4 & - \\
\hline
\end{tabular}


characteristic potentially enables the CTGS particles to be lightweight and highly deformable and crushable. In addition, there is negligible difference in the portions of the interparticle voids of $\mathrm{C}_{1}$ and $\mathrm{C}_{2}$, implying that the mixture design does not strongly affect the internal structure of the CTGS particles, and the increase of particle stiffness with amounts of cement is due to the increasing the cement bonds in the particle matrix.

\section{EFFECTS OF DEFORMATION AND CRUSHING OF CTGS PARTICLES ON STRESS-STRAIN BEHAVIORS IN TRIAXIAL CD TEST}

\section{Specimens Preparation}

The stress-strain behaviors of the CTGS were investigated by a series of triaxial CD tests on loose, dense specimens of $10 \mathrm{~cm}$ in diameter and $20 \mathrm{~cm}$ in height. The CTGS was used at natural water content (Table 2) for all test cases. The loose specimens were prepared directly into the triaxial cell by using a split mold where CTGS was placed by air pluviation with zero drop height. The dense specimens were formed in a steel mold for three layers, and each layer was compacted using 25 blows of $2.5 \mathrm{~kg}$ rammer from a drop height of $30 \mathrm{~cm}$, with a corresponding compaction energy $E_{\mathrm{c}}$ of $351 \mathrm{~kJ} / \mathrm{m}^{3}$. Specimens were isotropically consolidated at the confining pressures $\sigma_{\mathrm{c}}^{\prime}$ of 100,200 and $400 \mathrm{kPa}$, and then followed by shearing at the strain rate of $0.1 \% / \mathrm{min}$. Table 4 shows some of the properties of the CTGS specimens.

\section{Test Results and Discussion}

The stress-strain behaviors of $\mathrm{C}_{1}$ and $\mathrm{C}_{2}$ are characterized based on the relationship between the deviatoric stress, volumetric strain against axial strain, as shown in Fig. 10. It can be seen that the stress-strain behaviors in the cases of $C_{1}$ and $C_{2}$ behave in almost the same manner, i.e., the stress-strain relation shows the ductile behavior, and the overall contraction $\left(\varepsilon_{\mathrm{v}}>0\right)$ in the range of confining pressures, even in the dense state. These characteristics of CTGS are quite different from those normally found in dense granular materials with particles varying in size from fine to coarse (Bishop, 1966; Bolton, 1986; Indraratna et al., 1998) or crushable sands (Miura et al., 2003; Pender et al., 2006; Yoshimoto et al., 2010), in which the stress-strain behavior indicates a brittle or hardening tendency associated with the volumetric contraction at the initial stage of shearing and the positive dilatancy at a later stage of shearing $\left(\varepsilon_{\mathrm{v}}<0\right)$. However, ductile as well as contractive behavior was reported in some crushable granular materials with low strength particles. For instance, Arslan (2009) studied the influence of crushing on shear behavior using direct shear tests on manufactured granular materials of different particle strength, and demonstrated that the dilatant behavior of granular materials is repressed due to dominant particle crushing. Also, Liu (2010) conducted biaxial compres-
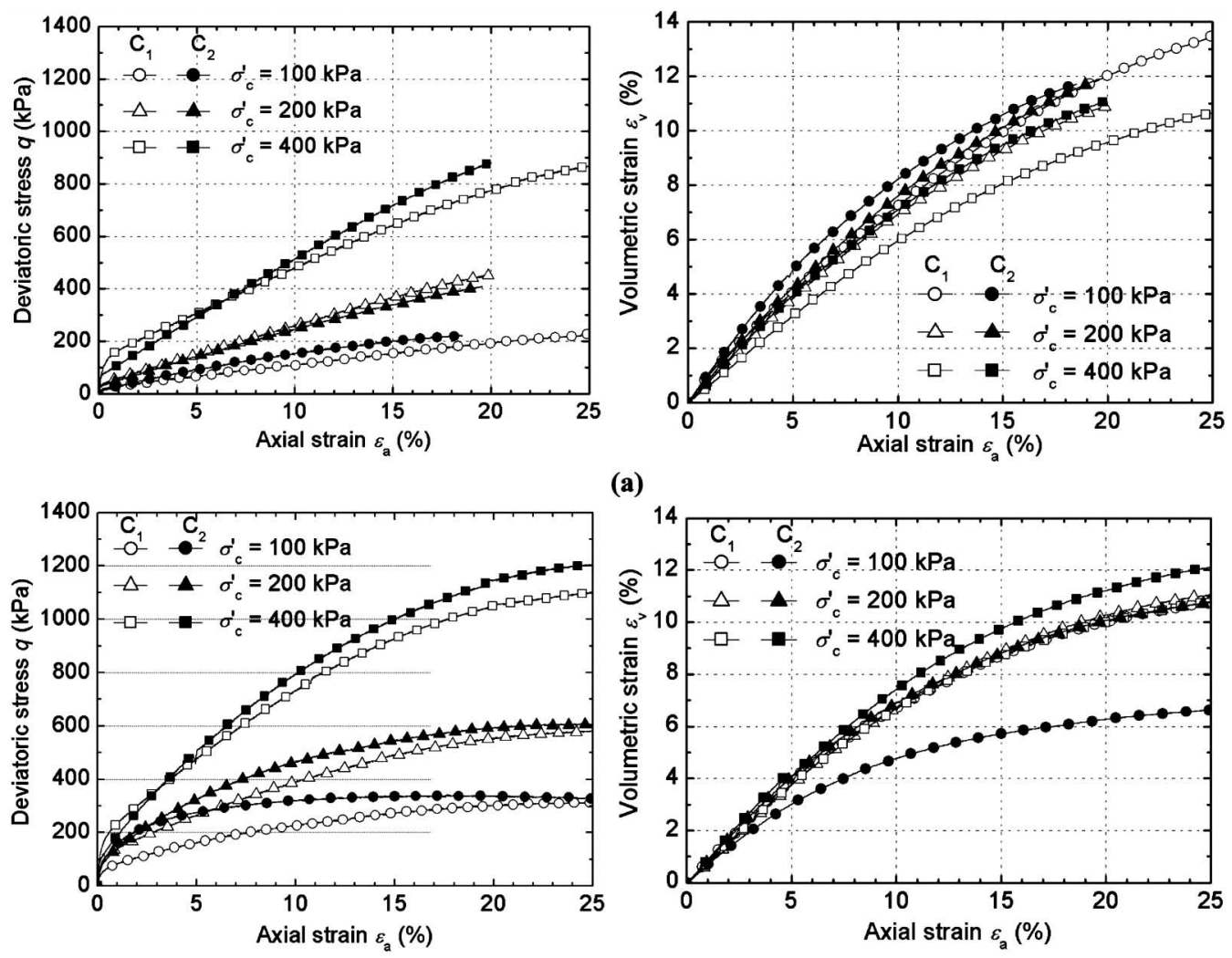

(a)

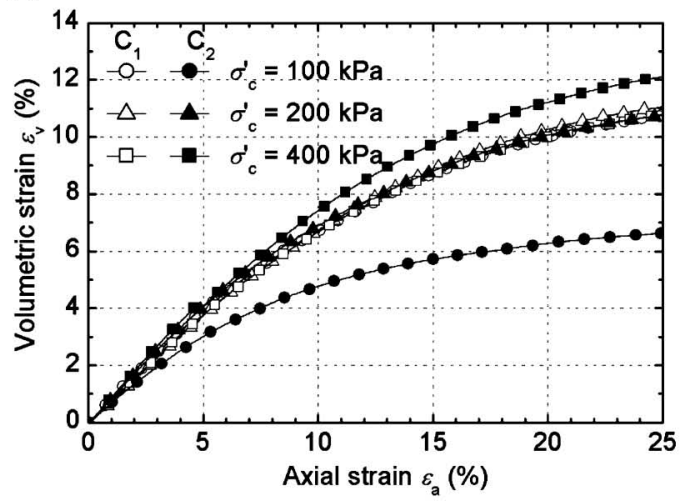

(b)

Fig. 10. Deviatoric stress and volumetric strain versus axial strain at different confining pressures: (a) Loose specimens, $E_{\mathrm{c}}=0 \mathrm{~kJ} / \mathrm{m}^{3}$ and (b) Dense specimens, $E_{\mathrm{c}}=351 \mathrm{~kJ} / \mathrm{m}^{3}$ 
sional tests on materials formed by crushable and deformable rods to investigate the breakage and deformation mechanisms of granular materials in the plane condition. The test results showed that strain hardening and a dilatancy were observed in the samples which suffered low lateral stress level, whereas strain softening and a compressive volume were seen in the samples compressed at high lateral stress. Accordingly, the pattern of stressstrain behaviors may be governed by a certain correlation between the particle strength, the stress level and the density of material. In the case of the CTGS with low strength particles, it can be demonstrated that particle crushing and particle deformation suppress the dilatancy

Table 4. Properties of CTGS specimens

\begin{tabular}{|c|c|c|c|c|c|}
\hline \multirow{2}{*}{\multicolumn{2}{|c|}{ Properties }} & \multicolumn{2}{|c|}{$\begin{array}{c}\text { Loose } \\
E_{\mathrm{c}}=0\left(\mathrm{~kJ} / \mathrm{m}^{3}\right)\end{array}$} & \multicolumn{2}{|c|}{$\begin{array}{c}\text { Dense } \\
E_{\mathrm{c}}=351\left(\mathrm{~kJ} / \mathrm{m}^{3}\right)\end{array}$} \\
\hline & & $\mathrm{C}_{1}$ & $\mathrm{C}_{2}$ & $\mathrm{C}_{1}$ & $\mathrm{C}_{2}$ \\
\hline \multicolumn{2}{|l|}{ Void ratio, $e$} & 3.33 & 2.96 & 1.89 & 1.76 \\
\hline \multicolumn{2}{|c|}{ Wet density, $\rho_{\mathrm{t}}\left(\mathrm{g} / \mathrm{cm}^{3}\right)$} & 0.930 & 0.950 & 1.329 & 1.301 \\
\hline \multicolumn{2}{|c|}{$\begin{array}{l}\text { Dry density before } \\
\text { consolidation, } \rho_{\mathrm{d}}\left(\mathrm{g} / \mathrm{cm}^{3}\right)\end{array}$} & 0.641 & 0.677 & 0.934 & 0.918 \\
\hline \multirow{3}{*}{$\begin{array}{l}\rho_{\mathrm{d}}\left(\mathrm{g} / \mathrm{cm}^{3}\right) \text { after } \\
\text { consolidation with } \\
\sigma_{\mathrm{c}}^{\prime}(\mathrm{kPa})\end{array}$} & 100 & 0.748 & 0.714 & 0.951 & 0.959 \\
\hline & 200 & 0.803 & 0.747 & 0.987 & 0.961 \\
\hline & 400 & 0.881 & 0.837 & 1.07 & 1.027 \\
\hline
\end{tabular}

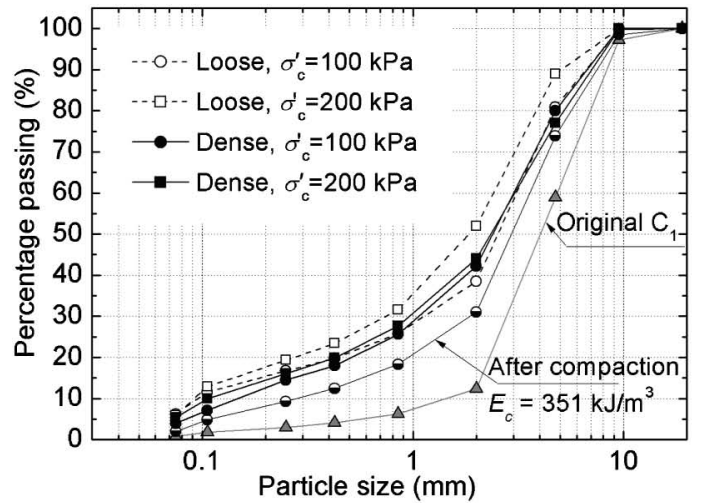

(a)

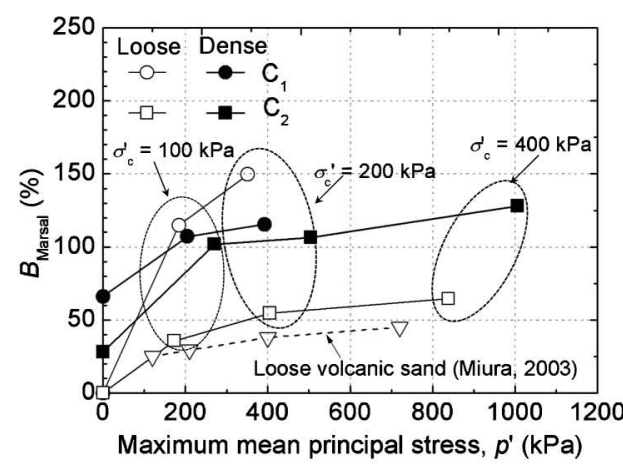

(c) of even the dense specimens.

The volumetric strain was shown to decrease with the confining pressure in the loose state and this tendency is greater in the dense state. This observation seems to be at odds with conventional geomaterials, where volumetric strain normally increases with the confining pressure. However, the volumetric strain in the shearing stage also depends on the density of the specimens after isotropic consolidation. Indeed, there was an appreciable increase of density after isotropic consolidation with the consolidated pressure in the loose specimens in comparison with that in the dense specimens, as is shown in Table 4. This increase in density occurred due to the void reduction as particles rearranged, and as the particles were crushed and deformed.

In addition, it is found in Fig. 10(b) for dense specimens and low confining pressure that the deviatoric stress of $C_{2}$ is larger than that of $C_{1}$, and that this tendency decreases with the axial strain level. Notably, as mentioned in Fig. 1(d) for unconfining compressive condition, the average values of particle strength of $C_{1}$ and $C_{2}$ are quite similar but the particle stiffness of $\mathrm{C}_{2}$ is considerably larger than that of $\mathrm{C}_{1}$. However, the advantage of the higher particle stiffness of $\mathrm{C}_{2}$ particles seems not to be mobilized when the stress level increases, as was the case when $400 \mathrm{kPa}$ of confining pressure was used.

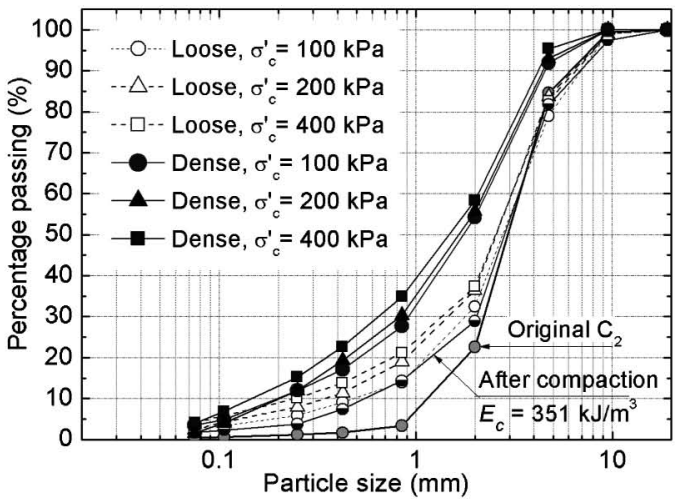

(b)

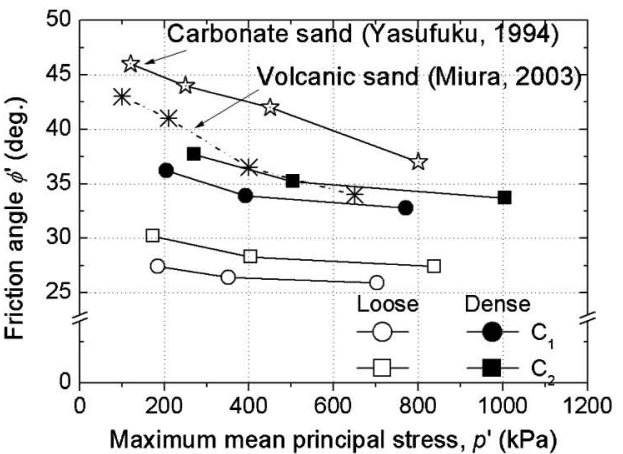

(d)

Fig. 11. Particles crushing: (a) $C_{1}$ type, (b) $C_{2}$ type, (c) $B_{\text {Marsal }}$ vs. maximum mean principal stress (d) Reduction of friction angle to maximum mean principal stress 


\section{Particle Crushing}

After testing, the specimens were carefully separated by hand pressure and analyzed by sieve. Figures 11(a) and 11(b) show the grading curves of $C_{1}$ and $C_{2}$ specimens before and after testing. A minor scatter in the test results could be generated due to the low strength of the CTGS particles: the low hand pressure could have disturbed integrity of the particles during separating. The difference between the original curves and those after testing indicates the extent to which the CTGS particles were crushed. It should be noted that the particle crushing is defined as the change in the size of particles due to by both breakage and the deformation of the individual particles. Numerous studies (Marsal, 1967; Lee and Farhoomand, 1967; Hardin, 1985; Miura et al., 2003) have shown that there are several factors which affect the amount of particle crushing of the granular materials, such as the stress level, stress path, and the amount of strain etc. Lade et al. (1996) incorporated the causes of particle crushing into the term of total energy input per unit volume of specimen as a more appropriate parameter for use when correlating with particle breakage, since calculations of the input energy involve the magnitude of both stresses and induced strains.

In this study, the Marsal method (1967) was used to quantify amount of particle crushing. Marsal's particle breakage factor, $B_{\text {Marsal }}$, was defined as the total of the difference in individual particle sizes between the initial and final grading curves. The difference in percentage remained is calculated for each sieve size, and it could be positive or negative. $B_{\text {Marsal }}$ is the sum of the differences with positive sign. Noticeably, the CTGS particles were almost all deformed and bonded with others in both loose and dense $C_{1}$ specimens subjected to a confining pressure of $400 \mathrm{kPa}$. In these cases, $B_{\text {Marsal }}$ could not be determined.

Figure 11(c) plots the relationship between $B_{\text {Marsal }}$ and the maximum effective mean principal stress, where the values corresponding to $p^{\prime}=0 \mathrm{kPa}$ in dense specimens were generated by compaction before testing. It can be seen that the amount of particle crushing increases with maximum mean principal stress in both the loose and dense states. In comparison with crushable volcanic sand subjected to the triaxial compression CD tests from the work done by Miura et al. (2003), the CTGS shows more particle crushing. In general, it can be observed that $C_{1}$ specimens experience more particle crushing than $C_{2}$ specimens especially at high stress. Loose $C_{1}$ specimens experienced much more particle crushing than loose $\mathrm{C}_{2}$ specimens because they were loaded to a larger strain level. This mechanism is still in question as the particle strength of $C_{1}$ and $C_{2}$ is similar. One of the possibilities affecting the extent of particle crushing is the fracture modes of the particles. The breakage of a single particle has been experimentally investigated for numerous studies for different materials (Yasufuku and Kwag, 1999; Nakata et al., 2001; Takei et al., 2001), and it has been reported that the pattern of fracture may be due to the breaking of the asperities and the surface grinding (a par- ticle is divided into one main part and small pieces of asperities) or major particle splitting (a particle is split into two or more equivalent parts), which depends on such variables as the size, shape and stiffness of the particles. Accordingly, depending on their stiffness, there could have different modes of fractures between the $C_{1}$ and $\mathrm{C}_{2}$ particles that influenced the change in size of the CTGS particles after testing.

In Fig. 11(d), it is observed that the friction angle (the secant angle, $\left.\phi^{\prime}\right)$ of $\mathrm{C}_{1}$ and $\mathrm{C}_{2}$ both drop against maximum mean principal stress. This reduction of friction angle is commonly considered as an effect of particle crushing in crushable granular materials, as seen in volcanic sand or in carbonate sand. In addition, the reduction of the friction angle of CTGS within the range of stress levels, about $4^{\circ}$ in dense state and $2^{\circ}$ in loose state, is smaller than that found in the other crushable sands. This is because the CTGS particles were also crushed at the low stress. However, the friction angle of $\mathrm{C}_{1}$ is only about $3^{\circ}$ lower than that of $\mathrm{C}_{2}$ and they still remain over $25^{\circ}$ in the loose state and $35^{\circ}$ in the dense state.

\section{INTRINSIC DEFORMATION AND CRUSHING OF THE CTGS PARTICLES}

\section{Experiments}

We were able to demonstrate that the deformation and crushing of the CTGS particles are key factor influencing on the overall stress-strain behaviors, strength and stiffness. The particle crushing as well as its effects on stressstrain relation of crushable materials has been widely studied in one or two dimensional compression conditions (Yasufuku and Kwag, 1999; Nakata et al., 2001; Takei et al., 2001; Arslan, 2009; Liu, 2010). However, it has not yet been well understood in triaxial loading condition. Therefore, it is worthy to clarify the intrinsic deformation and crushing of CTGS particles and be able to interpret the effects of deformation and crushing of particles on the stress-strain behaviors in triaxial loading.

The use of X-ray CT (Fig. 12) has been successfully applied to interpret the mechanical behaviors of geomaterials in numerous studies (Tani, 1997; Otani et al., 2000, 2005; Kikuchi et al., 2008). As an attempt to visually observe the detailed localized deformation and failure inside specimen during triaxial loading, the X-ray CT scans along with triaxial compression tests on specimens formed by the deformable and crushable particles of CTGS and rigid particles of conventional gravel employed. In this study, we used the test apparatus in the Port and Airport Research Institute, Japan (Kikuchi et al., 2008), consisting of a triaxial chamber located in the $\mathrm{X}$-ray shield box. For each scanning, an X-ray is generated and scanned throughout specimen at different angles. The CT-value obtained from scanning is proportional to the material density. For CT image processing, low CTvalues are indicated by dark grey or black and high CTvalues are indicated by light gray or white. Therefore, the darker region in CT image represents the lower density material and the brighter region reveals the higher density 


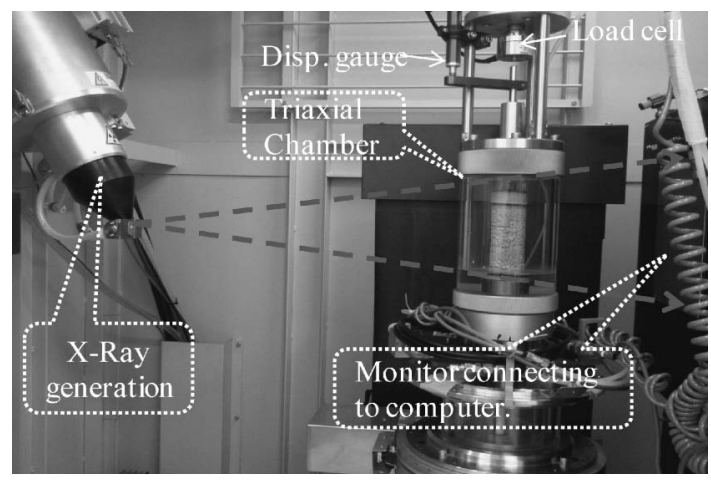

Fig. 12. Apparatus of $X$-ray CT scanner test and the triaxial cell

material. The method to construct the relationship between CT-values and density was well established in previous studies (Otani et al., 2000; Kikuchi et al., 2008). They demonstrated a linear relationship between the CTvalue and density. As the resulf, the grey level in CT image of specimen can be used to detect the distribution of material density within specimen.

In this study, tests were conducted on CTGS specimens at the natural water content (Table 2) and on gravel specimens with rigid particles. All tested specimens were $5 \mathrm{~cm}$ in diameter and $10 \mathrm{~cm}$ in height. The loose specimens of $\mathrm{C}_{1}, \mathrm{C}_{2}$ were prepared in a split mold by using a small hammer with mass and drop height of hammer are 200 gram and $10 \mathrm{~cm}$, respectively. Each specimen was formed by 40 blows in 4 layers, with a corresponding compaction energy of $30 \mathrm{~kJ} / \mathrm{m}^{3}$. This low level of compaction energy was used as an attempt to get specimens with good shape and sufficient density and to avoid particle crushing. The bulk density of $C_{1}$ and $C_{2}$ specimens was $0.93 \mathrm{~g} / \mathrm{cm}^{3}$ and $0.98 \mathrm{~g} / \mathrm{cm}^{3}$, respectively. The gravel depicted in Figs. 2(d) and Fig. 3 was used to form a loose specimen with bulk density of $1.88 \mathrm{~g} / \mathrm{cm}^{3}$ and water content of $3.5 \%$ by using the same compaction energy used to form the CTGS loose specimens. While a dense $\mathrm{C}_{2}$ specimen with a bulk density of $1.3 \mathrm{~g} / \mathrm{cm}^{3}$ was compacted in the mold using hammer of $400 \mathrm{gram}$, drop height of $15 \mathrm{~cm}$ with 60 blows in every 4 layers, the impact energy at level of $180 \mathrm{~kJ} / \mathrm{m}^{3}$. After consolidation under a confining pressure of 200 $\mathrm{kPa}$, all the specimens were sheared at the same strain rate of $0.1 \% / \mathrm{min}$. The axial loading was then interrupted at some levels of axial strain during shearing for X-ray scanning. In scans of the entire cross section of the specimens, a voxel size of $0.1 \mathrm{~mm} \times 0.1 \mathrm{~mm} \times 0.2 \mathrm{~mm}$ was used to obtain a series of sequent 500 cross sectional CT images for each scan. Three dimensional CT images of the specimens were achieved by reconstructing the sequent 2D CT images, allowing the alteration and interaction of the particles inside the specimens to be monitored during loading.

\section{Test Results}

Figure 13 shows the relationships between the deviatoric stress, the volumetric strain and the axial strain. The drop of the deviatoric stress at some strain levels was be-

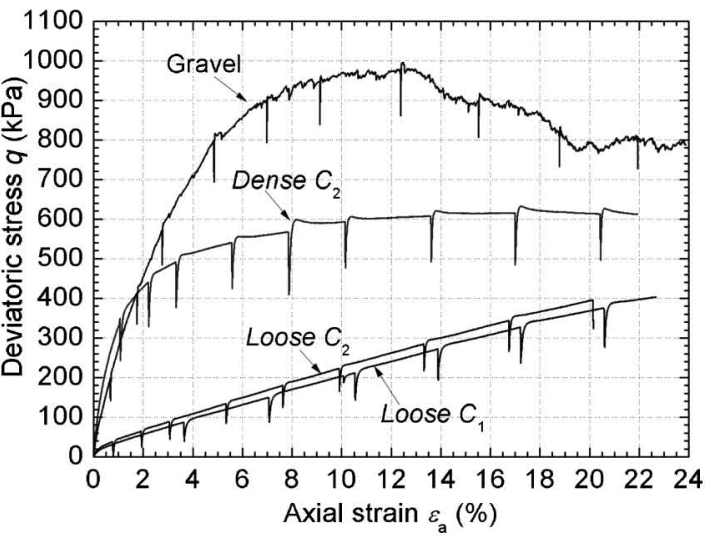

(a)

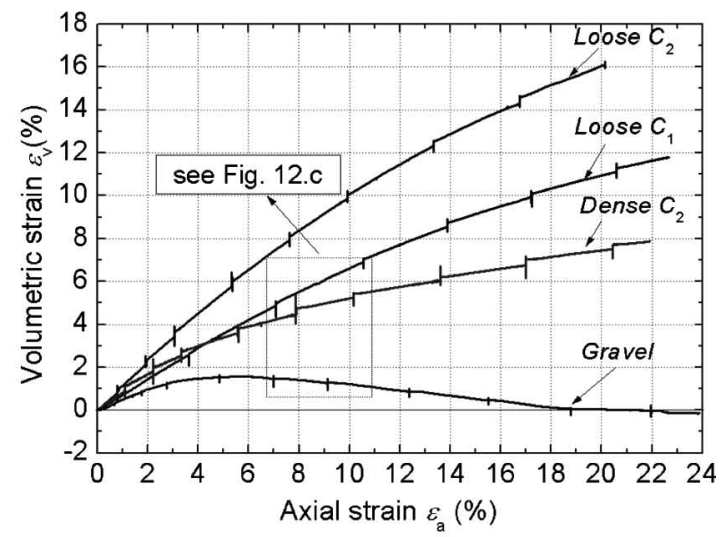

(b)

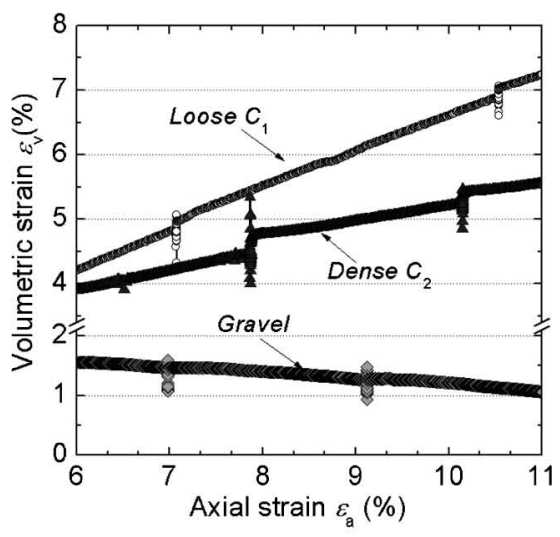

(c)

Fig. 13. Deviatoric stress and volumetric strain against the axial strain

cause of the stress relaxation as the X-ray scan. It can be seen that the stress-strain behaviors of the CTGS are consistent with thoses of the triaxial CD tests on the larger specimens in the previous section, which show a strain hardening and compressive deformation in both loose and dense states. However, the stress-strain curve obtained in the loose gravel specimen exhibits a brittle behavior with an obvious peak stress, followed by a softening in the post peak stage. As expected in Fig. 13(b), the loose gravel specimen shows a volumetric contraction at the initial stage of shearing and volumetric dilatancy at the large axial strain level. 


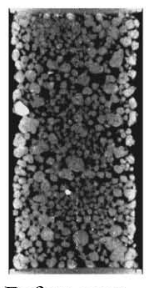

Before cons.

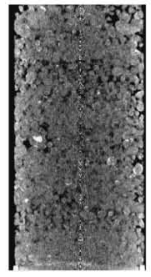

Before cons. $\varepsilon_{\mathrm{a}}=6.9 \%$

(a)

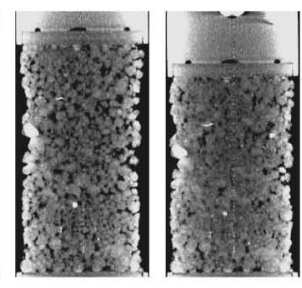

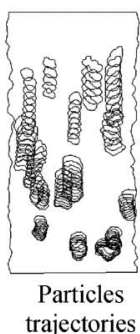

trajectories

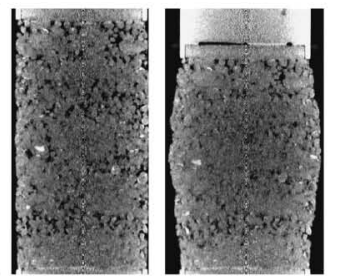

$\varepsilon_{\mathrm{a}}=18 \%$

(c)

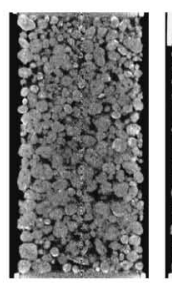

Before cons.

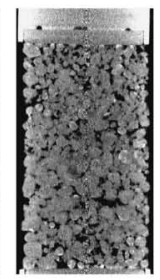

$\varepsilon_{\mathrm{a}}=7 \%$

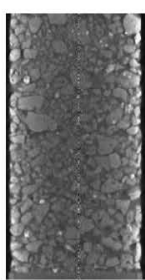

Before cons.

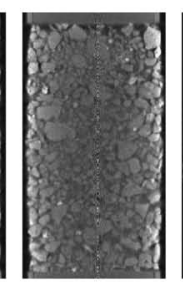

$\varepsilon_{\mathrm{a}}=7 \%$ (b)
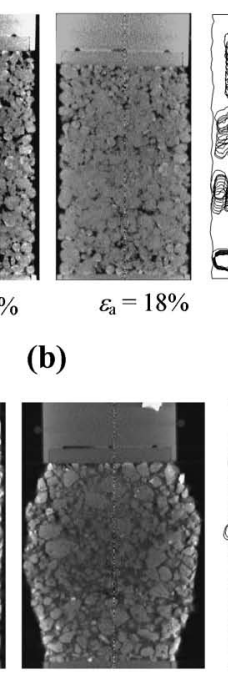

$\varepsilon_{\mathrm{a}}=21 \%$

(d)
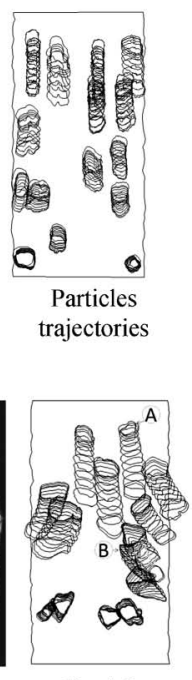

Particles

trajectories

Fig. 14. Vertical cross-section of specimens and trajectory of selected particles: (a) Loose $C_{1}$ specimen, (b) Loose $C_{2}$ specimen; (c) Dense $C_{2}$ specimen and (d) Loose gravel specimen

In addition, a fluctuation in volumetric strain is observed in Fig. 13(c) (the enlarged portion as depicted in Fig. 13(b)) when the axial loading was stopped for X-ray scanning. However the reason for this variation is not well understood. When the X-ray scanning was completed, an increment of volumetric strain appears in cases of the CTGS, especially in the dense state, but it does not appear in the case of gravel. This behavior is normally explained as the effects of viscosity in cases of fine particles clay or sand (Tatsuoka et al., 2002). Although more effort is needed to clarify this behavior in particular with regard to the coarse grain sizes of CTGS particles, it could be partly due to the viscous property of CTGS since the CTGS particles are comprised of fine clay particles. In addition, it is possible that that deformation of the CTGS particles subjected to local pressure may be associated with a shrinkage of the interparticle voids (Fig. 9), some of which would be closed so that excess pore water pressure is generated inside the particles. Subsequently, the dissipation of the excess pore water pressure is time dependent, and in turn, the deformation of the CTGS particles proceeds with time.

Figure 14 shows the vertical cross-sections at the center of the specimens before consolidation and at the different levels of axial strain. It can be seen that the brighter region reveals the size and shape of the CTGS particles, and the darker region represents the voids between particles. The voids reduce with the axial strain in all specimens. The dense $\mathrm{C}_{2}$ specimen and the loose gravel specimen showed bulging deformation but no clear shear band was observed.

The "ImageJ" software was employed to analyze the CT images, making each entire CTGS particle detectable by naked eyes. To observe the cross-sectional area of the particles accurately, the CT images were enlarged at high magnification, with each particle carefully outlined by hand sketching. As a result, the orbit of some selected particles during axial loading can be monitored by accumulating their positions between the different steps of the scanning at different strain levels. It should be noted that not all of the particles of the dense $C_{2}$ specimens, where particles are densely packed, could be seen well (see Fig. 14(c)). During shearing, each particle inside the specimens moves in the downward and radial directions and/or rotates around its own axis when vertical load increases. In Figs. 14(a) and 14(b) it is clear that the orbits of the typical particles in loose $C_{1}$ and $C_{2}$ specimens are almost direct to the vertical, indicating a small radial movement of particles. Particle rotation around its own axis also needs to be taken into account. However, the cross-section of each particle on the vertical cross-section at the center specimen is consistent with itself during the sequent steps of X-ray scanning, and thus the cross-sectional area can be used as a quantitative parameter to evaluate the change in the size of particles during testing.

The next step in our investigation was to calculate the normalized value of the cross-sectional areas of selected particles. The cross sectional area is defined as the crosssectional area of one particle at different steps of the Xray scanning divided by its original value before the isotropic consolidation. With high deformable and crushable potential, the number of particles which can be seen in their entirety during shearing is limited, especially in $C_{1}$ specimen, with only about 15 particles. In the $\mathrm{C}_{2}$ specimen, there are more particles which could be observed during shearing until later stage of shearing. We compared the average normalized values of between 15, 20 and 25 particles and found that there is only a minor change during loading. Therefore, although there is probably a scatter, it is assumed that the variation of the average normalized value of 15 selected particles can represent the change in the size of the particles inside the 
CTGS specimens that consist of particle deformation and particle crushing. Accordingly, the reduction in the average normalized values reveals the trend of particle deformation and particle crushing during shearing.

In Fig. 15(a), the average normalized value is slightly changed during consolidation in both the $C_{1}$ and $C_{2}$ specimens. When shearing starts, the normalized value is gradually reduced, or dramatically reduced in some particles. The average normalized values of $C_{1}$ and $C_{2}$ both drop against effective mean principal stress. However, the average normalized value of the $C_{1}$ specimen is lower than that of the $\mathrm{C}_{2}$ specimen with an increasing tendency which indicates the size reduction of $C_{1}$ particles is larger

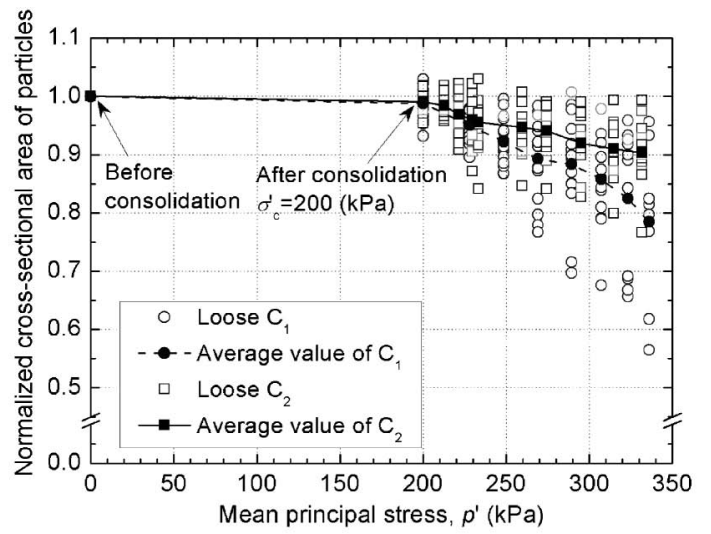

(a)

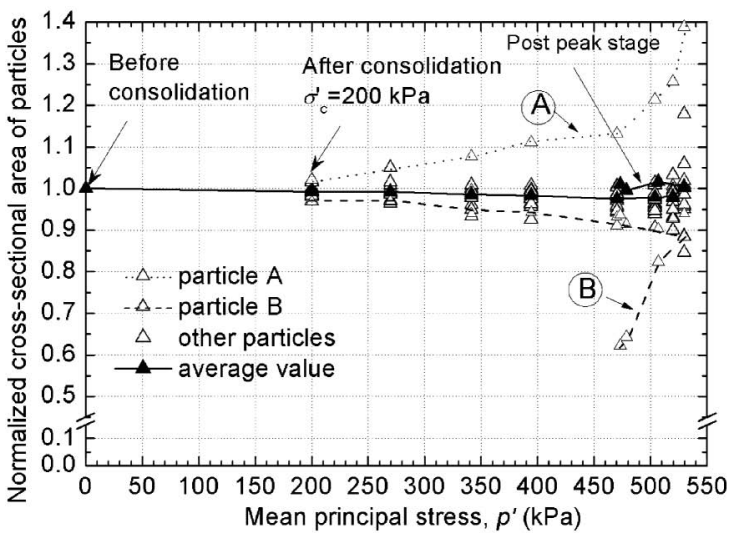

Fig. 15. Normalized cross-sectional area of the typical particles vs. mean principal stress: (a) loose CTGS specimens and (b) loose gravel specimen than for $\mathrm{C}_{2}$. It can be seen that the trend of particle deformation and particle crushing discussed here agrees with that of $B_{\text {Marsal }}$ found in Fig. 11(d), in which $C_{1}$ shows a higher value of $B_{\text {Marsal }}$ and increases as the mean principal stress increases. In addition, it was demonstrated that the changes in the size of the CTGS particles was not only induced by crushing (either in breaking of asperities and surface grinding or major particle splitting as mentioned in previous section) but also by the shrinkage of the particles due to particle deformation.

The same result for the gravel specimen is shown in Fig. 15(b), where the normalized value varies in both two sides of unity especially at the near and post peak stage. In Fig. 14(d), the paths of the selected particles are directed in both the vertical and horizontal directions, from which the relative motions between adjacent particles can be recognized. For examples, variations of the normalized value of particle A and particle B (the positions of A and B are depicted in Fig. 14(d)) indicate the rotational and radial motions of these particles during shearing. In another effort for more visibility, Fig. 16 plots the relative positions of the selected particles at the different levels of axial strain in another test on the gravel specimen. The relative movements of sliding and rolling between adjacent particles during shearing are clear in this figure. However, the average normalized value, also calculated from 15 arbitrary selected particles, remains close to unity during testing that indicates small change in size of the gravel particles. This consolidates the validity of the analysis method when normalized values are used to quantify the amount of particle crushing and the particle deformation of the CTGS particles.

In order to interpret the distinct characteristics of the stress-strain behaviors of the CTGS from conventional granular materials, the theory of the sliding and rolling motions within the regular packing of spheres (Fig. 17(a)) were employed to interpret the peak point of the stressstrain curve and the concept of dilatancy in conventional sands (Lambe and Whitman, 1979). As the vertical load increases, the particles first come close to others, and this generates compressive deformation and an increase in shear resistance (Fig. 17(b)). The subsequent stress-strain behaviors depend on the micro-mechanism of shearing between particles. In Fig. 17(c), when particles are in contact, in order to cause failure, the shear stress at the contact points between rigid particles not only overcomes the
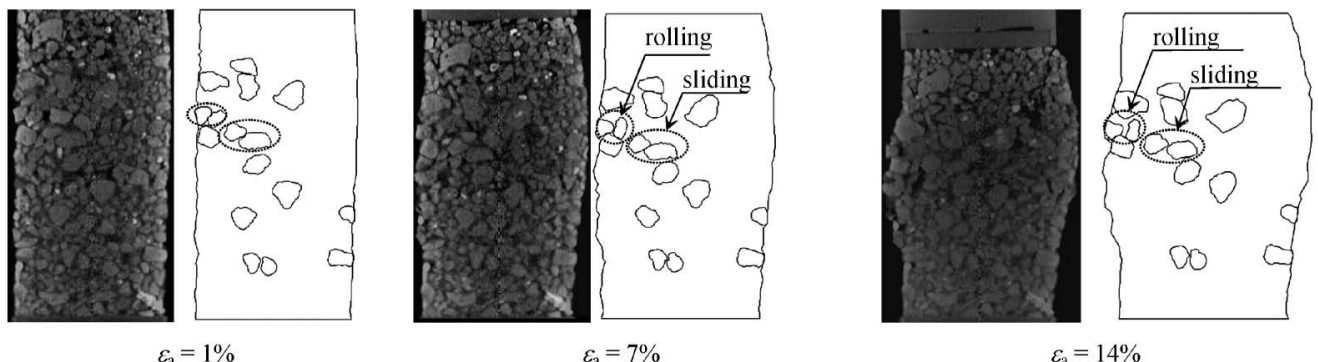

Fig. 16. Relative movements of the gravel particles during shearing 


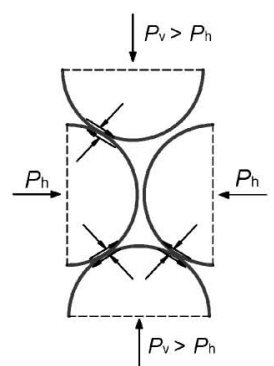

(a)

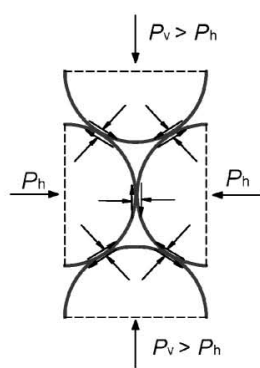

(b)

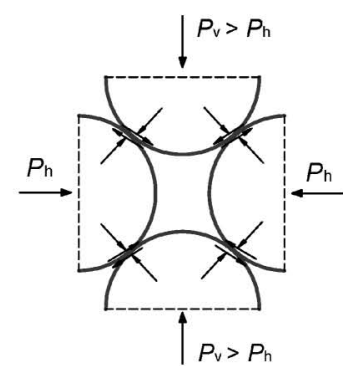

(c)

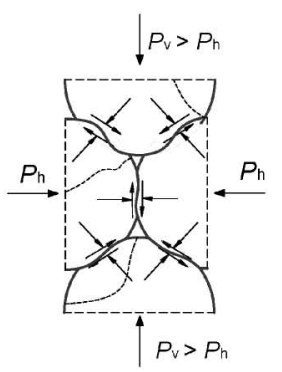

(d)

Fig. 17. The concept of packing of spheres: (a) particles in loose state, (b) particles in contact, (c) movement of rigid particles and (d) movement of deformable particles

frictional resistance but also causes particles to move up and move over others. Shear resistance is now generated by both frictional resistance at the contact parts between particles and an additional component arising from shearing against interlocked particles. These motions of rigid particles are accompanied by an increase of volume or positive dilatancy, and are followed by a decreasing degree of interlocking that generates shear stress reduction at the post peak stage. However, in case of the crushable CTGS particles (Fig. 17(d)), when the stress components at the contact points increase, the local failure induced by particle deformation and particle crushing are dominant in comparison to that arising from the sliding and rolling between the individual particles. The progression of the rearrangement of particles and stress redistribution increases the density of the specimen. As the result, the shear resistance of the overall material increases, and the deviatoric stress does not attain any obvious peak strength but continuously increases with further straining.

\section{CONCLUSIONS}

This paper presents a comprehensive investigation on the micro-structure, the deformation and the crushing of CTGS particles, as well as their effects on stress-strain behaviors of the CTGS. The deformation and crushing of the CTGS particles and the relative sliding and rolling of the gravel particles during triaxial testing were visually monitored by a CT images analysis. The following major conclusions are reached:

- The size, particle size distribution and particle strength of the CTGS particles are not strongly influenced by the mixing proportions of cement and polymer presented in this paper. However, the particle stiffness of the CTGS particles is increased, increasing the stiffness of the overall material.

- The CTGS particles contain interparticle voids. This vesicular characteristic gives lightweight and low strength particles, and high deformable and crushable potential. Indeed, considerable particle crushing and particle deformation due to compaction and triaxial loading was observed.

- The deformation and crushing of the CTGS particles govern its stress-strain behaviors, as it exhibits ductile behavior and contractive deformation during shearing, regardless of the initial density. In addition, a decreasing tendency of the friction angle with confining pressure was observed as the effect of particle crushing and particle deformation as the imposed stress increases.

- The localized failure of the CTGS with deformable and crushable particles and gravel with rigid particles was investigated by the X-ray CT scanner along with CD triaxial tests. The test results verified the pattern of stress-strain behaviors of deformable and crushablegrain granular materials and rigid-grain granular materials. The dominance of local failure due to deformation and crushing of the crushable particles suppresses the dilatancy that comes with ductile behavior and contractive deformation, whereas shear failure generated by sliding and rolling motions is associated with brittle stress-strain relationships and dilatant deformation.

\section{REFERENCES}

1) Arslan, H. (2009): Analysis of the influence of crushing on the behaviour of granular materials under shear, Granular Matter, 11, 87-97.

2) Bishop, W. A. (1966): The strength of soils as engineering materials, Geotechnique, 16(2), 89-130.

3) Bolton, M. D. (1986): The strength and dilatancy of sands, Geotechnique, 36(1), 65-78.

4) Chew, S. H., Kamruzzaman, H. M. and Lee, F. H. (2004): Physicochemical and engineering behaviour of cement treated clays, Journal of Geotechnical and Geoenvironmental Engineering, ASCE, 130(7), 696-706.

5) Chiu, C. F., Zhu, W. and Zhang, C. L. (2008): Yielding and shear behaviour of cement-treated dredged materials, Engineering Geology, 103, 1-12.

6) Dong, P. H., Hayano, K., Takahashi, H. and Morikawa, Y. (2009): Mechanical characteristics of lean-mixed granular cement treated soil from consolidated drained triaxial tests, Int. Symp. Geo. Eng., Ground Improvement, and Geosynthetics for Sustainable Mitigation and Adaptation to Climate Change Including Global Warming, Bangkok, Thailand.

7) Dong, P. H., Hayano, K., Takahashi, H. and Morikawa, Y. (2010a): Applicability of cement treat granulate soil for subgrade material, 11th Int. Conference on Asphalt Pavements, Nagoya, Japan.

8) Dong, P. H., Hayano, K., Takahashi, H. and Morikawa, Y. (2010b): Effects of mixture design on the mechanical properties of 
cement treat granulate soil, 6th Int. Congress on Environmental Geotechnics (6ICEG), New Delhi, India.

9) Fonseca, A. V., Cruz, R. C. and Consoli, N. C. (2009): Strength properties of sandy soil-Cement admixtures, Geotech. Geol. Eng., 27, 681-686.

10) Hardin, B. O. (1985): Crushing of soil particles, Journal of Geotechnical and Geoenvironmental Engineering, ASCE, 111(10), 1177-1192.

11) Horpibulsuk, S., Miura, N. and Nagaraj, T. S. (2005): Claywater/cement ratio identity for cement admixed soft clays, Journal of Geotechnical and Geoenvironmental Engineering, ASCE, 131(2), 187-192.

12) Indraratna, B., Ionescu D. and Christie, D. (1998): Shear behaviour of railway ballast based on larger-scale triaxial test, Journal of the Soil Mechanics and Foundation Division, ASCE, 124(5), 15318.

13) Kamali, S., Bernard, F., Abriak, N. E. and Degrugilliers, P. (2008): Marine dredged sediments as new materials resource for road construction, Waste Manage., 28, 919-928.

14) Kikuchi, Y., Nagatome, T. and Mitarai, Y. (2008): Change of engineering properties of cement treated clay by mixed with tire chips, Scrap Tire Dirived Geomaterials-Opportunities and ChallengeHazarika and Yasuhara, London, ISBN 978-0-415-46070-5.

15) Lade, P. V., Yamamuro, J. A. (1996): Significant of particle crushing in granular materials, Journal of Geotechnical Engineering, ASCE, 122(4).

16) Lambe, W. T. and Robert, W. V. (1979): Soil Mechanics, SI Version, ISBN 0-471-02261-6.

17) Lee, K. L. and Farhoomand, I. (1967): Compressibility and crushing of granular soils in anisotropic triaxial compression, Canadian Geotechnical Journal, 4(1), 68-86.

18) Liu, E. (2010): Breakage and deformation mechanisms of crushable granular materials, Computers and Geotechnics, 37,723-730.

19) Lorenzo, G. and Bergado, T. (2004): Fundamental parameters of cement-sdmixed clay-new approach, Journal of Geotechnical and Geoenvironmental Engineering, ASCE, 130(10), 1042.

20) Marsal R. J. (1967): Large scale testing of rockfill materials. Journal of the Soil Mechanics and Foundation Division, ASCE, 93(6), 117-141.

21) Miura, N., Horpibulsuk, S. and Nagaraj, T. S. (2001): Engineering behaviour of cement stabilized clay at high water content, Soils and Foundations, 41(5), 33-44.

22) Miura, S., Yagi, K. and Asonuma, T. (2003): Deformationstrength evaluation of crushable volcanic soils by laboratory and insitu testing, Soils and Foundations, 43(4), 47-57.

23) Nakata, T. and Miura, S. (2007): Change in void structure due to particle breakage of volcanic coarse-grained soil and its evaluation, JSCE Journal of Geotechnical and Geoenviromental Engineering, 63(1), 224-236.

24) Nakata, Y., Hyodo, M., Hyde, A., Kato, Y. and Murata, H. (2001): Microscopic particle crushing of sand subjected to high pressure one-dimensional compression, Soils and Foundations,
41(1), 69-82.

25) Otani, J., Mukunoki, T. and Obara, Y. (2000): Application of Xray CT method for characterization of failure in soils, Soils and Foundations, 40(2), 111-118.

26) Otani, J., Mukunoki, T. and Kikuchi, Y. (2005): Visualization for engineering property of in-situ light weight soils with air foams, Soils and Foundations, 42(3), 93-105.

27) Pender, M. J., Wesley, L. D., Larkin, T. J. and Pranjoto, S. (2006): Geotechnical properties of a pumice sand, Soil and Foundations, 46(1), 69-81.

28) Rekik, B. and Boutouil, M. (2009): Geotechnical properties of dredged marine sediments treated at high water/cement ratio, Journal of Geo-Marine Letters, 29, 171-179.

29) Sariosseiri, F. and Muhunthan, B. (2009): Effect of cement treatment on geotechnical properties of some Washington State soils, Engineering Geology, 104, 119-125.

30) Takahashi, H., Morikawa, Y., Ichikawa, E., Hayano, K. and Okusa Y. (2010): Model tests on compressibility and bearing capacity of lean-mixed granular cement treated soil, JSCE Journal of Geotechnical and Geoenviromental Engineering, 66(2), 236-249.

31) Takei, M., Kusakabe, O. and Hayashi, T. (2001): Time-dependent behaviour of crushable materials in one-dimensional compression test, Soils and Foundations, 41(1), 97-121.

32) Tang, Y. X., Miyazaki, Y. and Tsuchida, T. (2001): Practices of reused dredging by cement treatment, Soils and Foundations, 41(5), 129-143.

33) Tani, K. (1997): X-ray computed tomography technique to observe shear banding in dense sands, Proc. of IS-Nagoya '97, Pergamon, 315-320.

34) Tatsuoka, F., Uchida, K., Imai, K., Ouchi, T. and Kohata, Y. (1997): Properties of cement treated soil in Trans-Tokyo Bay Highway project, Ground Improvement, 1(1), 37-57.

35) Tatsuoka, F., Ishihara, M., Benedetto, H. D. and Kuwano, R. (2002): Time-dependent shear deformation characteristics of geomaterials and their simulation, Soils and Foundations, 42(2), 103-129.

36) Trembay, H., Duchesne, J., Locat, J. and Leroueil, S. (2002): Influence of the nature of organic compounds on fine soil stabilization with cement, Can. Geotech. J., 39, 535-546.

37) Tsuchida, T., Takeuchi, D., Okumura, T. and Kishida, T. (1996): Development of light-weight fill from dredging, Environmental Geotechnics, Proc. of the 2nd International Congress on Environmental Geotechnics, Balkema, 415-420.

38) Yasufuku, N. and Kwag, J. M. (1999): Significance of soil particle fragmentation strength related to soil crushability, Proc. of the 11th Asian Resional Conf. on Soil Mechanics and Geotechnical Engineering, Seoul, 1, Balkema, 149-152.

39) Yoshimoto, N., Wakatsuki, Y. and Hyodo, M. (2010): Particle characteristics and static shear strength of Clinker ash, 6th Int. Congress on Environmental Geotechnics (6ICEG), New Delhi, India. 